\title{
Manajemen Penghimpunan dan Pendistribusian Dana ZIS Di LAZISNU Kota Padangsidimpuan
}

\author{
Risna Hairani Sitompul ${ }^{1}$, Ade Awari Butar-Butar², Wenni Sakinah Lbs ${ }^{3}$ \\ 1,2,3 Institut Agama Islam Negeri Padangsidimpuan \\ 1,2,3 Jl. T. Rizal Nurdin Km. 4,5 Sihitang, Kota Padangsidimpuan \\ Email: risnahairanistp@gmail.com
}

\begin{abstract}
Abstrak
Indonesia merupakan penduduk muslim yang paling banyak sehingga Indonesia memiliki potensi dana ZIS. Sumber pendanaan dari dana ZIS dapat dimanfaatkan untuk kekuatan pemberdayaan ekonomi, pemerataan pendapatan dan menggerakkan perekonomian. Tujuan penelitian untuk mengetahui manajemen penghimpunan dan pendistribusian dana ZIS di LAZISNU Kota Padangsidimpuan. Metode penelitian yang dilakukan dengan cara kualitatif dengan data primer: melakukan wawancara langsung langsung dari narasumber dan data sekunder dapat berupa bukti pencatatan, pembukuan dan data-data mengenai penelitian. Hasil penelitian menunjukkan bahwa metode penghimpunan dana ZIS dilakukan dengan Gerakan KOIN NU, media sosial, rekening dan barcode pembayaran. Penghimpunan dana dengan KOIN NU yang tersebar di beberapa daerah di Provinsi Sumatera Utara. Manajemen pengelolaan dana dilakukan dengan pembukuan secara rinci mengenai jumlah dan infak yang diterima serta penyaluran dana setiap kegiatan. Pengumpulan dana dilakukan 2 kali seminggu. Pendistribusian dana LAZISNU Padangsidimpuan dalam 5 bidang yaiu sosial keagamaan, ekonomi, pendidikan, renovasi dan kesehatan.
\end{abstract}

Kata Kunci: Dana, LAZISNU, Penghimpunan, Pendistribusian, ZIS

\begin{abstract}
Indonesia is the largest Muslim population so Indonesia has the potential for ZIS funds. Funding sources from ZIS funds can be used to strengthen economic empowerment, distribute income and drive the economy. Research objectives to determine the management of fundraising through the KOIN NU movement, social media, payment accounts, and barcodes, to know the distribution of funds raised by LAZISNU under the LAZISNU Padangsidimpuan implementation program. The research method is carried out qualitatively with primary data: conducting direct interviews from sources and secondary data in the form of evidence of recording, bookkeeping, and data regarding research. The results of the research were using the KOIN NU movement, social media, accounts, and payment barcodes. The collection of funds with KOIN NU which is spread across several areas in North Sumatra Province has increased and resulted in higher funds collected than others. Fund management is carried out carefully and is recorded in detailed books regarding the amount and infak received and the distribution of these funds for each activity. Funds are collected twice a week. LAZISNU Padangsidimpuan fund distribution in 5 fields, namely socio-religion, economy, education, renovation, and health.
\end{abstract}




\section{PENDAHULUAN}

Negara Indonesia merupakan Negara yang luas dan memiliki sumber daya alam yang sangat berpotensi untuk meningkatkan ekonomi dan mampu memenuhi kebutuhan masyarakat tetapi Indonesia mengalami kendala yaitu dengan kebodohan, kemiskinan, dan pengangguran yang semakin meningkat. Hal ini mengakibatkan angka kemiskinan dan kesejahteraan masyarakat Indonesia akan semakin menurun. Badan Pusat Statistika (BPS) Republik Indonrsia pada tahun 2019 tingkat kemiskinan mencapai 9,41\%. Instrumen yang dapat mengatasi masalah kemiskinan di Indonesia dapat menggunakan ZIS (zakat Infak dan Shodaqoh). Indonesia merupakan penduduk muslim yang paling banyak sehingga Indonesia memiliki potensi dana ZIS. Sumber pendanaan dari dana ZIS dapat dimanfaatkan untuk kekuatan pemberdayaan ekonomi, pemerataan pendapatan dan menggerakkan perekonomian.

Zakat sudah ada di dalam syariat Allah kepada umat Islam, agar mereka mengeluarkan sebagian hartanya sebagai zakat sesuai dengan kadar ketentuan yang ada. Zakat berasaskan syariat Islam yaitu amanah, kemanfaatan, keadilan, kepastian hukum, terintegrasi, dan akuntabilitas. LAZISNU dalam sistem pengelolaan zakat yang lebih professional bagi masyarakat (Sa'diyah, 2020). Zakat merupakan pembersih diri dan harta dari kemungkinan diperoleh dengan jalan tidak halal. Membayar zakat juga membuat harta semakin tumbuh dan berkembang. Seorang yang membayar zakat karena keimanannya nicaya memperoleh kebaikan yang banyak. Allah SWT berfirman, "Pungutlah zakat dari sebagian kekayaan mereka dengan zakat itu kamu membersihkan dan mensucikan mereka”. (QS : At-Taubah : 103). Pengelolaan ZIS di Indonesia sudah dilakukan pada tahun 1990 an memiliki ciri khas seperti pemberian langsung oleh muzakki (Rafiqi, 2019).

Infak adalah mengeluarkan sebagian harta benda yang dimiliki untuk kepentingan yang mengandung kemaslahatan. Dalam infak tidak ada nishab. Karna itu infak boleh dikeluarkan oleh orang yang berpenghasilan tinggi atau rendah, disaat lapang atau sempit (QS Ali 'Imran [3] :134). Infak merupakan ibadah social yang sangat utama. Kata infak mengandung pengertian bahwa menafkahkan harta di jalan Allah tidak akan mengurangi harta, tetapi justru akan semakin menambah harta. Sedangkan sedekah adalah pemberian sesuatu yang bersifat kebaikan, baik berupa barang maupun jasadari seseorang kepada orang lain tanpa mengharapkan suatu imbalan apapun selain ridha Allah. Hukum dan ketentuan shodaqoh sama dengan ketentuan infak. Hanya saja jika infak berkaitan dengan materi. Shodaqoh/sedekah memiliki arti yang lebih luas (Rafiqi, 2019).

Termasuk pemberian yang sifanya non materi, seperti memberi jasa, mengajarkan ilmu pengetahuan, dan memdoakan orang lain. Sedekah menunjukkan, pengertian tentang kenenaran keimanan seseorang (shaddaqa). Dengan bersedekah berarti seseorang tidak 
hanya meyakini keimanannya dalam hati, tetapi juga mengaflikasikannya dalam kehidupan nyata (Ansori, 2018).

Dalam pemberdayaannya, zakat dilakukan dengan cara produktif yaitu memberikan manfaat kepada penerima untuk menmbah income (masukan) dan membantu dalam mendapatkan lapangan pekerjaan untuk meningkatkan kesejahteraan keluarga masyarakat pada umumnya. Apabila dana ZIS dikelola dengan baik maka ZIS akan dapat mempergunakan dana yang berasal dari masyarakat dan dimanfaatkan untuk kesejateraan masyarakat sehingga perlunya kerjasama pemerintah, masyarakat dan pengelola ZIS. Syarat pemberdayaan yang dilakukan untuk modal usaha, keterampilan, biaya pendidikan dan pelatihan (Ansori, 2018).

\section{KAJIAN TEORITIS}

Peran diartikan sebagai perangkat tingkah yang diharapkan dimiliki oleh orang yang berkedudukan dalam masyarakat. Sedangkan peranan merupakan tindakan yang dilakukan oleh seorang dalam suatu peristiwa (Mukmin, 2014). Peranan (role) merupakan aspek dinamis kedudukan (status). Apabila seseorang melaksanakan hak dan kewajibannya sesuai dengan kedudukannya, dia menjalankan suatu peranan. Pembedaan antara kedudukan dengan peranan adalah untuk kepentingan ilmu pengetahuan. Keduanya tak dapat dipisah-pisahkan karena yang satu tergantung pada yang lain dan sebaliknya. Tak ada peranan tanpa kedudukan atau kedudukan tanpa peranan. Setiap orang mempunyai macam-macam peranan yang berasal dari pola-pola pergaulan hidupnya (Mukmin, 2014).

Peranan merupakan kata peran yang mendapatkan imbuhan dengan akhiran -an. Maknanya jika dilihat dalam KBBI (Kamus Besar Bahasa Indonesia) adalah tindakan yang dilakukan oleh seseorang dalam suatu peristiwa. Jika kata peranan dimasukkan dalam sebuah kalimat yang memiliki subyek, maka bisa bermakna tindakan yang dilakukan oleh subyek tertentu dalam suatu peristiwa. Oleh karena itu, ketika kata peranan disandingkan dengan kata zakat seperti pada kalimat peranan zakat, maka dapat diartikan sebagai tindakan yang dilakukan oleh zakat dalam suatu peristiwa (KBBI, n.d.)

\section{Zakat, Infak dan Sedekah}

Zakat termasuk rukun Islam, Zakat mulai disyari'atkan pada bulan syawal tahun kedua Hijriyah sesudah pada bulan Ramadhan diwajibkan zakat fitrah, kemudian diwajibkan zakat maal atau kekayaan Zakat dari segi bahasa berarti "Berkah, Bersih, Baik dan Meningkat". Sedangkan secara bahasa At-Thaharah (kesucian), Al-barakah (keberkahan), An-Nama' (pertumbuhan/perkembangan) (Teuku Muhammad Hasbi Ash Shiddiqy, 2006). Penjelasan makna secara harfiah tersebut mengerucut pada pengertian zakat sebagai proses pembersihan diri yang didapatkan setelah pelaksanaan kewajiban membayar zakat. Sedangkan pengertian 
zakat menurut syara' yaitu memberikan sebagian harta kepada yang berhak menerimanya sesuai dengan aturan-aturan yang telah ditentukan dalam Al-Qur'an (Fazlur Rahman, 1996).

Madzhab Maliki mendefinisikan zakat dengan mengeluarkan sebagian harta yang khusus yang telah mencapai nishab kepada orang-orang yang berhak menerimanya. Sedangkan menurut madzhab Hambali zakat ialah hak yang wajib dikeluarkan dari harta yang khusus untuk kelompok yang khusus pula (Fanani, 2000). Di dalam Al-Qur'an, Allah SWT telah menyebutkan tentang zakat dan shalat sejumlah 82 ayat. Dari sini dapat disimpulkan bahwa setelah shalat, zakat merupakan rukun Islam terpenting. Pelaksanaan shalat melambangkan baiknya hubungan seseorang dengan Tuhannya, sedangkan zakat adalah lambang harmonisnya hubungan antar sesama manusia. Hal ini menunjukkan bahwa zakat mempunyai arti yang sangat signifikan baik dalam kehidupan religi dan sosial (Fanani, 2000). Adapun beberapa tujuan zakat adalah sebagai berikut pertama, mengangkat derajat fakir miskin dan membantunya keluar dari kesulitan hidup dan penderitaan. Kedua, membantu memecahkan masalah yang dihadapi oleh orang yang berutang, ibnu sabil, dan mustahiq lainnya. Ketiga, membina tali persaudaraan sesama umat Islam. Keempat, menghilangkan sifat kikir dari pemilik harta. Kelima, membersihkan sifat dengki dan iri hati dari orang-orang kurang mampu. Keenam, menjembatani jurang pemisah antara yang kaya dengan yang kurang mampu dalam suatu masyarakat. Ketujuh, mengembangkan rasa tanggung jawab sosial pada diri seseorang, terutama pada mereka yang mempunyai harta dan terakhir mendidik manusia untuk berdisplin menunaikan kewajiban dan menyerahkan hak orang lain yang ada padanya.

Orang-orang yang berhak menerima zakat, pertama fakir, adalah orang yang tidak mempunyai harta dan usaha, atau mempunyai harta atau usaha yang kurang dari seperdua kecukupannya, dan tidak ada orang yang berkewajiban memberi belanjanya. Kedua, kurang mampu, adalah orang yang mempunyai harta atau usaha sebanyak seperdua kecukupannya atau lebih, tetapi tidak sampai mencukupi (Sulaiman Rasjid, 1992). Ketiga, amil zakat, adalah pengurus zakat yang ditunjuk oleh pemimpin atau wakilnya. Mereka bertugas mengumpulkan zakat dari orang-orang kaya, menjaga, menghitung dan membaginya. Keempat, muallaf, adalah orang yang diberi zakat dengan maksud melunakkan hati mereka atau untuk meneguhkan hati mereka di atas Islam. Kelima, budak, maksud al-Riqob disini adalah para budak yang mukatab, yang dijanjikan akan merdeka bila membayar sejumlah harta kepada tuannya. Budak yang telah mengikat perjanjian yang sah dengan tuannya, tetapi tidak mampu membayarnya dapat diberikan zakat untuk membantu mereka memerdekakan dirinya. Keenam, gharim, adalah orang yang menanggung utang dan tidak mampu melunasi. Ketujuh, fisabilillah, Yang termasuk ke dalam kelompok Fi sabilillah ini adalah mereka para pejuang yang berperang di jalan Allah secara suka rela tanpa mendapatkan bayaran. Sehingga mereka berhak untuk menerima zakat, tetapi meskipun mereka termasuk orang yang berjuang atau 
berperang di jalan Allah dan mendapatkan gaji maka mereka tidak boleh untuk menerima zakat. Terakhir, ibnu sabil, adalah musafir yang berada jauh dari negerinya, kehabisan uang atau terjadi sesuatu yang menghabiskan seluruh uangnya (Ali Mahmud Uqaily, 2017).

Infak ditinjau dari segi bahasa berarti "membelanjakan", Sedangkan menurut syari'at Infak adalah mengeluarkan sebagian dari harta atau pendapatan (penghasilan) untuk suatu kepentingan kemanusiaan yang diperintahkan ajaran Islam (Abdul Mujieb \& Mabruri Tholhah Syafi'ah, 1994). Dalam kajian fiqh Islam infak dibedakan dari zakat dan shadaqah, zakat merupakan derma yang sudah ditetapkan jenis, jumlah dan waktu pelaksanaannya sedangkan infak tidak ada ketentuan mengenai jenis dan jumlah harta yang akan dikeluarkan serta tidak ditentukan kepada siapa diberikan (Abdul Mujieb \& Mabruri Tholhah Syafi'ah, 1994). Sedangkan sedekah berasal dari kata shodaqa yang terdiri dari tiga huruf Shod-dal-qaf, berarti sesuatu yang benar atau jujur.sedekah bisa diartikan mengeluarkan harta di jalan Allah, sebagai bukti kejujuran atau kebenaran iman seseorang. Sedekah adalah pemberian berupa sesuatu yang berguna bagi orang lain yang memerlukan bantuan (fakir, miskin) dengan tujuan beribadah (mencari pahala) kepada Allah semata. Sedekah pada prinsipnya sama dengan infak hanya saja sedekah memiliki pengertian yang lebih luas. Sedekah dapat berupa bacaan tahmid, takbir, tahlil, istighfar maupun bacaan-bacaan kalimat tayyibah lainnya, sedekah juga dapat berupa pemberian benda atau uang, bantuan tenaga atau jasa serta menahan diri dari tidak berbuat kejahatan. Sedekah adalah keseluruhan amal kebajikan yang dilakukan setiap pribadi muslim untuk menciptakan kesejahteraaan sesama umat manusia, termasuk untuk kelestarian lingkungan hidup dan alam semesta ciptaan illahi guna memperoleh hidayah dan ridha Allah Subhanahu Wa Ta'ala (Makhlul Ilmi, 2002).

Tabel 1.

Persamaan dan Perbedaan Zakat, Infak dan Sedekah

\begin{tabular}{|c|c|c|c|}
\hline & Zakat & Infak & Sedekah \\
\hline Definisi & $\begin{array}{l}\text { Hak yang wajib dalam } \\
\text { waktu tertentu untuk } \\
\text { golongan tertentu. }\end{array}$ & $\begin{array}{l}\text { Menafkahkan sesuatu } \\
\text { kepada orang lain dengan } \\
\text { ikhlas dan karena Allah } \\
\text { semata }\end{array}$ & $\begin{array}{l}\text { Menafkahkan sesuatu kepada } \\
\text { orang lain dengan ikhlas dan } \\
\text { karena Allah semata }\end{array}$ \\
\hline Hukum & $\begin{array}{l}\text { Wajib apabila telah } \\
\text { mencapai nisab }\end{array}$ & Wajib dan sunnah & Sunnah \\
\hline Waktu & $\begin{array}{l}\text { Ada batasan } \\
\text { musiman (haul) }\end{array}$ & $\begin{array}{l}\text { Terus menerus tanpa ada } \\
\text { batasan }\end{array}$ & $\begin{array}{l}\text { Terus menerus tanpa ada } \\
\text { batasan }\end{array}$ \\
\hline Bentuk & Berupa materi & Berupa materi & Berupa materi dan non materi \\
\hline
\end{tabular}

Sumber: diolah peneliti

JISFIM: Journal of Islamic Social Finance Management, Volume 2, No 1 Tahun 2021 http://jurnal.iain-padangsidimpuan.ac.id/index.php/JISFIM 


\section{Kesejahteraan Masyarakat}

Kesejahteraan merupakan titik ukur bagi masyarakat yang berarti bahwa telah berada pada kondisi yang sejahtera. Pengertian kesejahteraan menurut kamus bahasa Indonesia berasal dari kata sejahtera yang mempunyai makna aman, sentosa, makmur, dan selamat, terlepas dari segala macam gangguan, kesukaran, dan sebagainya. Kata sejahtera mengandung pengertian dari bahasa sansekerta "catera" yang berarti payung. Dalam konteks kesejahteraan, "catera" adalah orang yang sejahtera, yakni orang yang dalam hidupnya bebas dari kekurang mampuan, kebodohan, ketakutan, atau kekhawatiran sehingga hidupnya aman dan tentram, baik secara lahir maupun batin (Departemen Pendidikan Nasional, 2005). Undang-Undang Nomor 13 tahun 1998 menjelaskan juga tentang arti dari kesejahteraan. Kesejahteraan didefinisikan sebagai suatu tata kehidupan dan penghidupan sosial baik material maupun spiritual yang diliputi rasa keselamatan, kesusilaan, dan ketentraman lahir batin yang memungkinkan bagi setiap warga negara untuk mengadakan pemenuhan jasmani, rohani, dan sosial yang sebaik-baiknya bagi diri, keluarga, serta masyarakat dengan menjunjung tinggi hak dan kewajiban asasi manusia sesuai dengan Pancasila (Almizan, 2016).

Konsep “kesejahteraan” yang memasukkan tujuan kemanusiaan dan keruhaniaan, tentu akan berakibat pada keharusan mendiskusikan secara ilmu ekonomi apa hakekat tujuan kesejahteraan tersebut dan bagaimana merealisasikannya. Tujuan-tujuan konsep kesejahteraan tersebut tidak hanya mencakup soal kesejahteraan ekonomi dalam arti materi semata, tetapi juga mencakup permasalahan persaudaraan manusia dan keadilan sosialekonomi, kesucian kehidupan, kehormatan individu, kehormatan harta, kedamaian jiwa dan kebahagiaan, serta keharmonisan kehidupan keluarga dan masyarakat.

\section{METODE PENELITIAN}

Jenis Penelitian yang digunakan dalam penelitian ini adalah penelitian kualitatif deskriptif dengan pendekatan studi kasus. Studi kasus merupakan studi yang mengeksplorasi suatu kasus secara mendalam, mengumpulkan informasi seara lengkap dengn menggunakan berbagai prosedur pengumpulan data berdasarkan waktu yang telah ditentukan. Kasus ini dapat berupa suatu peristiwa, aktivitas, proses dan program (Sa'diyah, 2020). Lokasi penelitian ini diambil adalah LAZISNU Padangsidimpuan jalan Masjid Raya Baru No. 24 a Komplek Masjid Agung Al Abror Kota Padangsidimpuan 22711. Subjek penelitian yang dipilih dalam penelitian ini bertindak sebagai informan yang menjadi sumber informasi bagi peneliti guna kebutuhan data penelitian yaitu Bapak Zulpan Harahap S.S, M.Pd, SM. Kom sebagai Ketua LAZISNU di Kota Padangsidimpuan. Data yang diperoleh atau dikumpulkan langsung dari narasumber yang berada di LAZISNU Padangsidimpuan, data tersebut secara langsung 
berhubungan dengan obyek penelitian dan mampu memberikan informasi yang dibutuhkan dalam penelitian ini, melalui wawancara yang berkaitan dengan permasalahan yang diteliti. Data primer antara lain: catatan hasil wawancara, dan data-data mengenai penelitian (Nasrudin, 2017). Teknik pengumpulan data diperoleh dari sumber langsung (data primer) atau data diperoleh dari sumber tidak langsung (data sekunder). Analisis data merupakan penguraian data dalam bentuk kalimat yang tersusun secara sistematis, jelas dan terperinci yang kemudian diinterreasikan untuk memperoleh suatu kesimpulan. Analisis data dilakukan dengan memberikan penguraian data dalam bentuk kalimat yang tersusun secara sistematis, jelas dan terperinci yang kemudian diinterreasikan untuk memperoleh suatu kesimpulan. Keabsahan data dalam penelitian ini dilakukan dengan menggunakan teknik triangulasi.

\section{HASIL DAN PEMBAHASAN}

\section{Sejarah Berdirinya LAZISNU}

Lembaga Amil Zakat Infak Shadaqah Nahdlatul Ulama (LAZISNU) yang didirikan pada tahun 2004 sesuai dengan amanah Muktamar NU ke-31 yang digelar di Asrama Haji Donohudan, Boyolali, Jawa Tengah. Sebagaimana cita-cita awal berdirinya NU CARE LAZISNU sebagai lembaga nirlaba milik perkumpulan Nahdlatul Ulama (NU) senantiasa berkhidmat untuk membantu kesejahteraan umat serta mengangkat harkat sosial melalui pendayagunaan dana Zakat, Infak, Sedekah (ZIS) dan dana-dana Corporate Social Responsibility (CSR).

Ketua Pengurus Pusat (PP) LAZISNU yang pertama adalah Prof. Dr. H. Fathurrahman Rauf, M.A., seorang akademisi dari Universitas Islam Negeri (UIN) Syarif Hidayatullah, Jakarta. Pada periode pertama, Lazisnu memfokuskan pada internal lembaga. Tahun 2010 diselenggarakan Muktamar Nahdlatul Ulama (NU) ke-32, di Makassar, Sulawesi Selatan, memberi amanah kepada KH. Masyhuri Malik sebagai Ketua PP LAZISNU menggantikan Prof. Dr. H. Faturrahman Rauf, MA. Ketua terpilih dipercaya memimpin PP LAZISNU untuk masa kepengurusan 2010-2015. Hal itu telah diperkuat oleh SK Pengurus Besar Nahdlatul Ulama (PBNU) No.14/A.II.04/6/2010 tentang Susunan Pengurus LAZISNU periode 2010-2015. Hingga akhir kepengurusan, Lazisnu terus berkembang dan bersaing dengan lembaga lainnya.

Pada tahun 2015, berdasarkan surat keputusan Nomor: 15/A.II.04/o9/2015, Pengurus Pusat LAZISNU dibentuklah kepungurusan baru untuk masa khidmat 2015-2020 yang diketuai oleh Syamsul Huda, SH (Yulianti, 2019). Pada tahun 2018, berdasarkan surat Keputusan Walikota Padangsidimpuan No.381KPTS/2019 tentang Pengangkatan Pimpinan BAZNAS Kota Padangsidimpuan periode 2019 - 2024 oleh Bapak Zulpan Harahap, S.S, M.Pd, M.Kom.

\section{NU CARE - LAZISNU}

JISFIM: Journal of Islamic Social Finance Management, Volume 2, No 1 Tahun 2021 http://jurnal.iain-padangsidimpuan.ac.id/index.php/JISFIM 
NU CARE-LAZISNU adalah rebranding dan/atau sebagai pintu masuk agar masyarakat global mengenal Lembaga Amil Zakat, Infak, dan Sedekah Nahdlatul Ulama (LAZISNU). NU CARE-LAZISNU berdiri pada tahun 2004 sebagai sarana untuk membantu masyarakat, sesuai amanat muktamar NU yang ke-31 di Asrama Haji Donohudan, Boyolali, Jawa Tengah. NU CARE secara yuridis-formal dikukuhkan oleh SK Menteri Agama No. 65/2005 untuk melakukan pemungutan Zakat, Infak, dan Sedekah kepada masyarakat luas (ISLAM, n.d.). NU CARE-LAZISNU merupakan lembaga nirlaba milik perkumpulan Nahdlatul Ulama (NU) yang bertujuan, berkhidmat dalam rangka membantu kesejahteraan umat; mengangkat harkat sosial dengan mendayagunakan dana Zakat, Infak, Sedekah serta Wakaf (ZISWAF) (DAAIM, 2020).

\section{Sejarah dan Perkembangan NU CARE-LAZISNU}

Dimulai sejak 2004 (1425 Hijriyah) Lembaga Amil Zakat, Infak, dan Sedekah Nahdlatul Ulama (LAZISNU) lahir dan berdiri sebagai amanat dari Muktamar Nahdlatul Ulama (NU) yang ke31, di Asrama Haji Donohudan, Boyolali, Jawa Tengah. Ketua Pengurus Pusat (PP) LAZISNU yang pertama adalah Prof. Dr. H. Fathurrahman Rauf, M.A., yakni seorang akademisi dari Universitas Islam Negeri (UIN) Syarif Hidayatullah, Jakarta. Tahun 2005 (1426 Hijriyah) secara yuridis-formal LAZISNU diakui oleh dunia perbankan dan dikukuhkan oleh Surat Keputusan (SK) Menteri Agama No.65/2005. Selanjutnya, pada tahun 2010 (1431 Hijriyah) pada Muktamar Nahdlatul Ulama (NU) ke-32, di Makassar, Sulawesi Selatan, memberi amanah kepada KH. Masyhuri Malik sebagai Ketua PP LAZISNU dan menggantikan Prof. Dr. H. Faturrahman Rauf, MA. KH. Masyhuri dipercaya memimpin PP LAZISNU untuk masa kepengurusan 2010-2015. Hal itu telah diperkuat oleh SK Pengurus Besar Nahdlatul Ulama (PBNU) No.14/A.II.04/6/2010 tentang Susunan Pengurus LAZISNU periode 20102015. Pada tahun 2015 (1436 Hijriyah) dengan berdasarkan Surat Keputusan Nomor: 15/A.II.04/09/2015, Pengurus Pusat LAZISNU masa khidmat 2015-2020 diketuai oleh Syamsul Huda, SH. Tahun 2016 (1437 Hijriyah) dalam upaya meningkatkan kinerja dan meraih kepercayaan masyarakat, NU CARE-LAZISNU menerapkan Sistem Manajemen ISO 9001:2015, yang dikeluarkan oleh badan sertifikasi NQA dan UKAS Management System dengan nomor sertifikat: 49224 yang telah diterbitkan pada tanggal 21 Oktober 2016. Dengan komitmen manajemen MANTAP (Modern, Akuntable, Transparan, Amanah dan Profesional). Sampai saat ini, NU CARE telah memiliki jaringan pelayanan dan pengelolaan ZIS di 12 negara, di 34 provinsi, dan 376 kabupaten/kota di Indonesia. NU CARE sebagai lembaga filantropi akan terus berupaya untuk meningkatkan kepercayaan dari para donatur yang semua sistem pencatatan dan penyalurannya akan bisa dilihat secara real time melalui sistem IT (Ahmad, 2021). 


\section{Manajemen Penghimpunan Dana ZIS di LAZISNU Kota Padangsidimpuan}

Penghimpunan dana ZIS di LAZISNU Kota Padangsidimpuan dilakukan dengan beberapa cara yaitu:

a. Gerakan KOTAK Infak Nahdlatul Ulama (KOIN NU)

Gerakan Kotak Infak Nahdhatul Ulama (KOIN NU) merupakan gerakan penghimpunan dana, infak dan masyarakat nahdliyin mulai dari masyarakat kelas atas sampai masyarakat kurang mampu secara ekonomi dan tidak menekankan pada nominalnya (Yulianti, 2019). Gerakan KOIN NU telah berdiri sejak tahun 2018. Berdasarkan wawancara dengan Bapak Zulpan Harahap, S.S.M.Pd.M.Kom selaku Ketua LAZISNU Padangsidimpuan bahwa Jumlah KOIN NU Padangsidimpuan berjumlah 4746 yaitu 4391 kotak kayu dan 355 kotak kaca. Pengumpulan dana dalam program Gerakan KOIN LAZISNU dilakukan dalam tiga tahap yakni:

a) Penyebaran KOIN NU

Pengurus Gerakan KOIN NU menyebarkan kotak kayu dan kotak kaca ke setiap warung warung seperti kios, rumah makan, restoran, counter HP, jual bahan bangunan, penginapan dan lain sebagainya yang ada di sekitaran Wilayah Kabupaten/Kota di Sumatera Utara seperti Kota Padang Sidempuan, Tapanuli Selatan, Tapanuli Utara, Simalungun, Serdang Bedagai, Deli Serdang, Medan, Batu Bara, Labuhan Batu Raya, Rantau Prapat, Labusel, dan Paluta.

b) Pengumpulan KOIN NU

Setiap sekali dua minggu, pengurus mengumpulkan koin dari warungwarung tersebut. Koin yang telah terkumpul selanjutnya dikumpulkan di kantor dan dihitung bersama oleh pengurus.

c) Penyaluran KOIN NU

Setelah dana terkumpul maka dana akan disalurkan untuk para penerima dana yang telah tercatat dan terdata. 


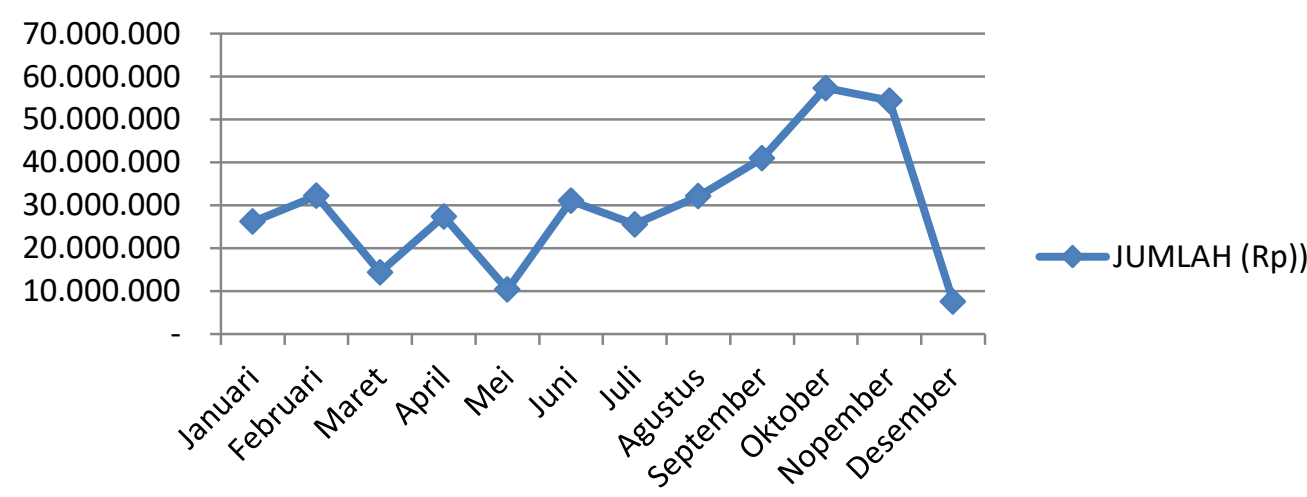

Gambar 1. Tren Dana ZIS yang Terhimpun melalui Gerakan KOIN NU Tahun 2020

Berdasarkan Gambar 1 di atas merupakan hasil data yang dieroleh dari LAZISNU Padangsidimpuan. Pengumpulan KOIN NU dilakukan dua minggu sekali. Pada bulan Januari 2020 perhitungan dilakukan mulai tanggal 9 Desember 2019 - 9 Januari 2020 dan kemudian perhitungan dimulai setiap tanggal 9 pada bulan berikutnya. Pada bulan Maret 2020 data diperoleh dari tanggal 11 Februari - 11 Maret 2020 mengalami perubahan setiap tanggal 11 bulan berikutnya dan sampai sekarang.

Berdasarkan hasil wawancara dengan Bapak Zulpan Harahap, S.S., M.Pd., M.Kom dan data yang diperoleh bahwa pengumpulan KOIN NU sangat berpengaruh pada pengumpulan dana LAZISNU NU. Pengumpulan KOIN NU selama tahun 2020 yang paling rendah pada bulan Mei sebesar Rp10.353.500,oo mengalami penurunan. Sejak bulan Agustus - Desember 2020, jumlah pengumpulan KOIN NU yang semakin meningkat. Pengumpulan KOIN NU yang paling tinggi pada bulan Desember 2020 sebesar Rp75.898.100,oo karena penyebaran KOIN NU semakin banyak di Propinsi Sumatera Utara. Pengumpulan KOIN NU bukan saja di sekitar Kota Padangsidimpuan tetapi di beberapa daerah di Provinsi Sumatera Utara yang samapai saat ini sudah memiliki 66 tim pengumpulan KOIN NU. Adanyua peningkatan jumlah dana dari hasil KOIN NU membuktikan bahwa adaya persepsi kepercayaan berpengaruh terhadap Gerakan KOINU LAZISNU (Annisatry Lubis et al., 2020).

b. Pengumpulan dana melalui Media Social, Rekening, dan Barcode Pembayaran

Selain gerakan KOIN NU, LAZISNU juga melakukan pengumpulan dengan dengan melalui media social, rekening dan barcode pembayaran sehingga akan mempermudah pengumpulan dana baik yang dekat maupun yang jauh dari lokasi LAZISNU NU Padangsidimpuan dan juga akan mempermudah melaksanakan infak. 


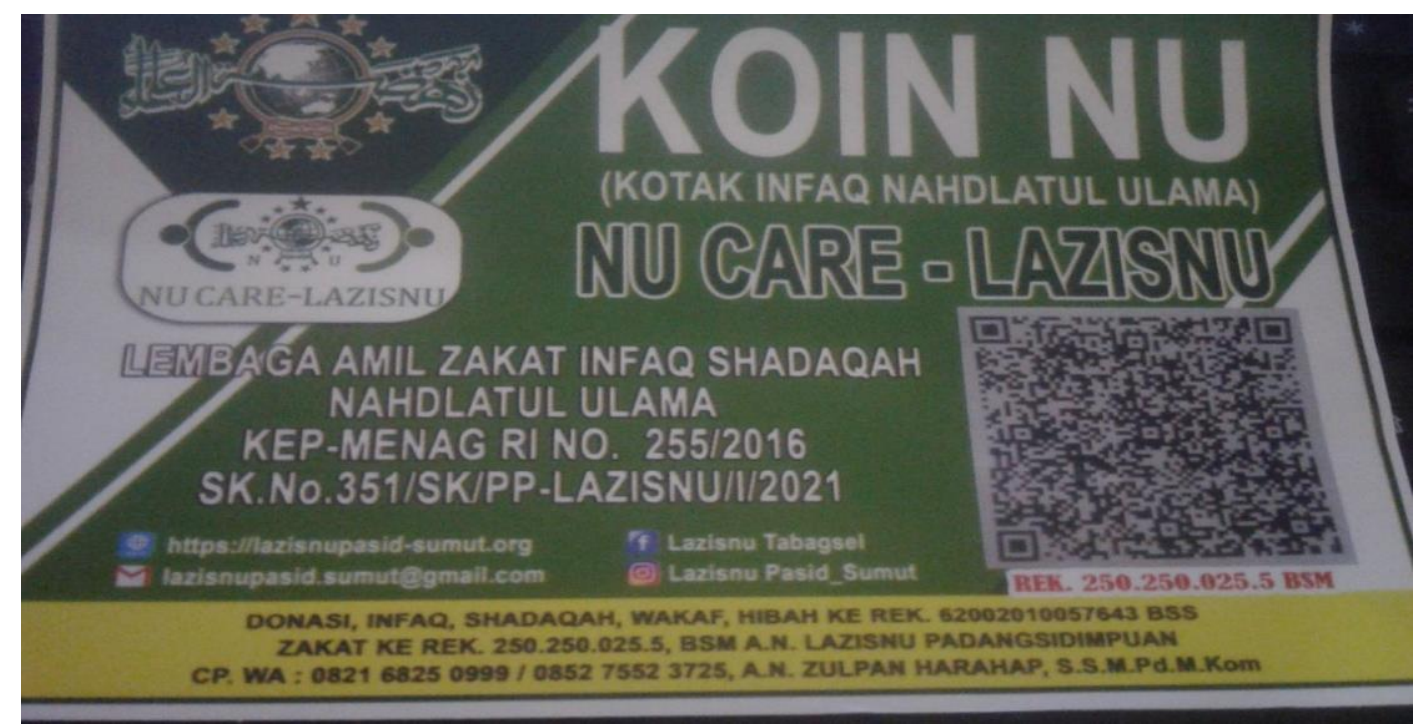

Gambar 2. Pengumpulan dana melalui Media Sosial, Rekening, dan

Barcode Pembayaran Tahun 2020

Zakat, infak, shadaqoh selaludisandingkan dalam kegiatan lembaga-lembaga social pengelola zakat. Jika hanya focus pada zakat maka perolehan materi maupun non materi akan sangat sedikit sehingga apabila digabungkan dana zakat, infak dan shadaqah maka akan meningkat dan idak adanya keterbatasan perolehan dana yang akan disalurkan pada muzakki (Rahman, 2019).

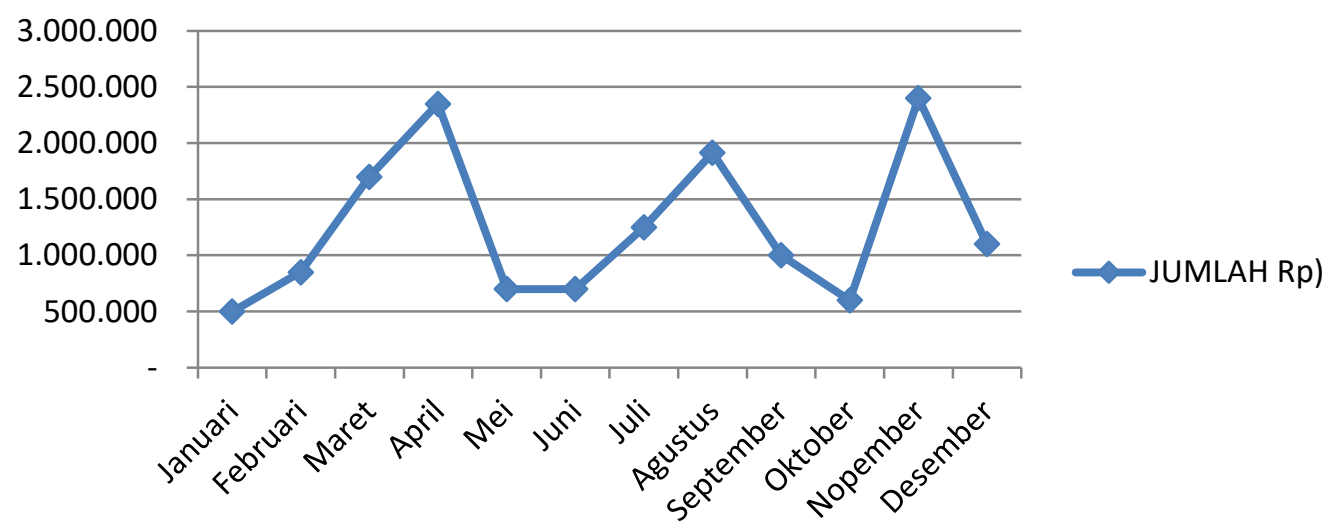

\section{Gambar 3. Tren Dana ZIS yang Terhimpun melalui Media Sosial, Rekening, dan Barcode Pembayaran}

Berdasarkan pengumpulan dana melalui media social, rekening, dan barcode Pembayaran bahwa jumlah dana yang diterima tidak menetap. Pengumpulan dana yang paling rendah di bulan Januari 2020 sebesar Rp500.00o dan pengumpulan dana yang paling tinggi pada bulan April 2020 sebesar Rp2.350.00o. Pengumpulan dana KOIN NU lebih tinggi dari 
pada pengumpulan dana melalui melalui media sosial, rekening dan barcode pembayaran sehingga penyebaran KOIN NU lebih ditingkatkan dengan peningkatan anggota Tim di seluruh daerah provinsi Sumatera Utara.

Kabupaten Pamekasan mendapat penghargaan BAZNAS award pada tahun 2018 sebagai kategori LAZNAS dengan pertyumbuha dana tertinggi dan terbaik. Hal inidapat kita lihat pada periode Mei - Agustus 2018, jumlah penerimaan LAZISNU sebesar Rp979.154.185,oo (Rafiqi, 2019). Pelaksanaan program LAZISNU dapat dilakukan dengan cara meningkatkan pelayanan terhadap masyarakat yaitu Gerakan KOIN NU. Menjemput dana zakat, infak dan shodaqoh yang ada didalam KOIN NU memberikan kepuasan dan kepercayaan Muzakki sehingga LAZISNU menjalankan pendistribusian dana sesuai amanah (Fatimah, 2019). Strategi penghimpunan dana ZIS di Jawa Tengah cabang pekalongan dilakukan dengan cara promosi dan sosialisasi melalui media social diantaranya facebook, istagram dan whatsapp, brosur, batik tv serta MMT. LAZIS juga bekerjasama dengan beberapa perusahaan dengan memberikan pelayanan jemput zakat dan bias juga melalui bank transfer ke rekening donasi (Wiqoyati, 2019) dan didukung dengan strategi digital (Nafiah, 2018).

Berdasarkan hasil wawancara dengan Bapak Zulpan Harahap, S.S.M.Pd.M.Kom selaku Ketua LAZISNU di Padangsidimpuan bahwa perolehan dana KOIN LAZISNU dikelola dengan cara mengalokasikan dana tersebut sebagai biaya operasional pengembangan usaha serta tasaruf. Proses pengelolaan tersebut dilaukan dengan cara cermat dan dicatat dalam pembukuan yang dibuat secara rinci mengenai jumlah dan infak yang diterima serta penyaluran dana tersebut. Hal ini dilakukan sebagai bentuk pertanggungjawaban pengurus dan amanah dari warga yang berinfak (Ansori, 2018).

\section{Manajemen Pendistribusian Dana ZIS di LAZISNU Kota Padangsidimpuan}

Dana ZIS terkumpul dari program Gerakan KOIN NU, Media Sosial, Rekening, dan Barcode Pembayaran didistribusikan lagi ke masyarakat dalam bentuk berbagai bantuan yang bermanfaat. Dana infak dari program LAZISNU di Padangsidimpuan didistribusikan dalam 5 bidang yaitu:

1. Sosial keagamaan seperti mengaji, memberikan mushaf alquran dan lain lain

2. Program karitas di bidang Ekonomi : bantuan untuk kebutuhan harian keluarga atau individu, pemenuhan hajat hidup bagi mereka yang paling tidak berdaya dan lain lain

3. Program karitas di bidang Pendidikan : bantuan untuk kebutuhan pendidikan formal individu berupa beasiswa dan pendidikan non formal dengan memberikan bimbingan belajar tanpa membayar atau gratis

4. Program karitas di bidang Renovasi : Renovasi tempat sekolah, jalan umum sekolah dan lain lain

JISFIM: Journal of Islamic Social Finance Management, Volume 2, No 1 Tahun 2021 http://jurnal.iain-padangsidimpuan.ac.id/index.php/JISFIM 
5. Program karitas di bidang Kesehatan: bantuan pengobatan, memberikan edukasi pencegahan dengan cara analisis, sebab-sebab dan diarahkan pencegahan penyakit dan biaya perobatan.

Pengelolaan dana KOIN NU mandiri cukup efektif dalam meningkatkan kesejahteraan masyarakat melalui program LAZISNU sehingga mampu menurunkan angka kemiskinan dan mampu memenuhi kebutuhan masyarakat di seluruh Indonesia (Yulianti, 2019). Upaya meningkatkan penghimpunan dana dan pendistribusian dana LAZISNU maka dapat membagikan porsi kerja dalam wilayah tertentu dengan baik dan terarah sesuai dengan struktur organisasinya (Sa'diyah, 2020).

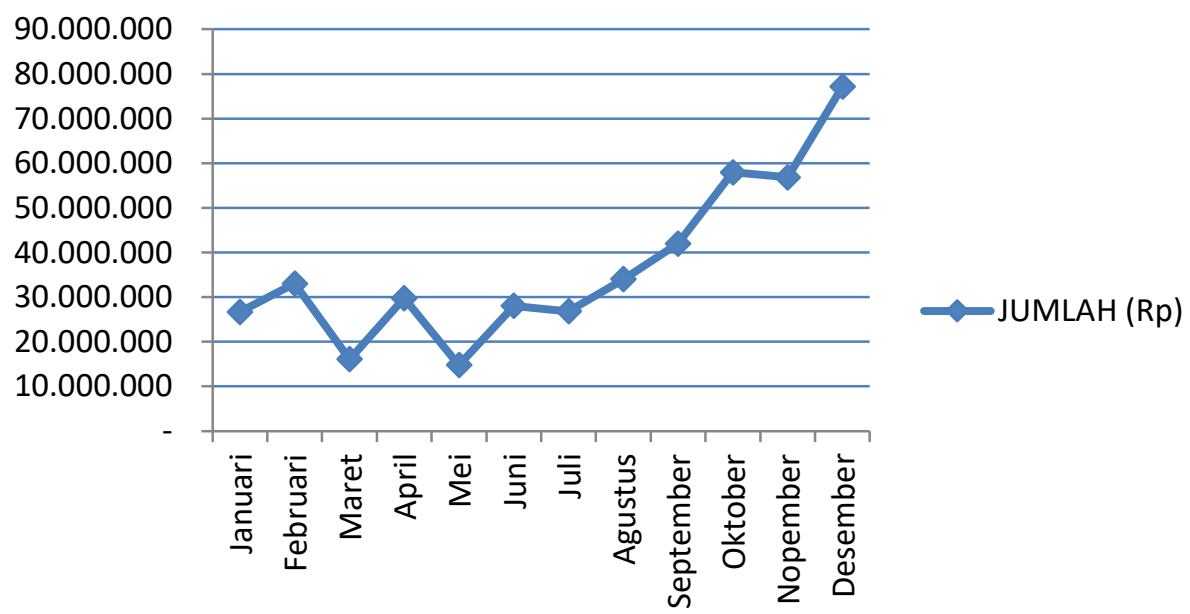

\section{Gambar 4. Tren Kenaikan Dana ZIS pada LAZISNU Kota Padangsidimpuan yang Didistribusikan Tahun 2020}

Pendistribusian dana yang dilakukan merupakan penggabungan pengumpulan dana baik KOIN NU maupun melalui media social, rekening dan barcode pembayaran. Berdasarkan hasil wawancara dengan Bapak Zulpan Harahap, S.S., M.Pd., M.Kom dan data yang diperoleh bahwa adanya pendistribusian dana setiap bulan sesuai dengan kebutuhan masyarakat. Pada bulan Mei 2020, penyaluran dana yang paling rendah sebesar Rp14.765.00o,oo karena penghimpunan dana baik dengan cara KOIN NU, media social, rekning dan barcode pembayaran mengalami penurunan sedangkan penyaluran dana yang paling tinggi pada bulan 
Desember 2020 sebesar Rp77.148.100,00 karena sesuai dengan peningkatkan jumlah KOIN NU di beberapa daerah di provinsi Sumatera Utara.

Implementasi penghimpunan dan pendistribusian dana akan berfungsi untuk membantu pengelolaan dan peranan zakat dalam meningkatkan kesejateraan mustahik dan LAZISNU dapat melaksnakan fungsinya sebagai program produktif dan konsumtif (Astuti, 2020). Program Gerakan KOIN NU memliki konsep yang diawali dengan penghimpunan dana dilanjutkan manajemen pengelolaan dana dan diakhiri dengan manajemen pendistribusian dana ZIS yang memiliki dampkpositif baik kepada mustahik maupun muzzakki (Maulana, 2020). Strategi program Gerakan KOIN NU yang dilakukan oleh LAZISNU mampu memberdayakan masyarakat sehingga meningkatkan kesejahteraan dengan cara memberikan bantuan berupa bahan makanan, material maupun uang tunai (Kharimah, 2019).

\section{KESIMPULAN}

Lembaga Amil Zakat Infak Shadaqah Nahdlatul Ulama (LAZISNU) yang didirikan pada tahun 20042004 sesuai dengan amanah Muktamar NU ke-31 yang digelar di Asrama Haji Donohudan, Boyolali, Jawa Tengah. NU CARE-LAZISNU merupakan lembaga nirlaba milik perkumpulan Nahdlatul Ulama (NU) yang bertujuan, berkhidmat dalam rangka membantu kesejahteraan umat; mengangkat harkat sosial dengan mendayagunakan dana Zakat, Infak, Sedekah, Wakaf (ZISWAF). Pelaksanaan Program Gerakan KOIN NU LAZISNU Padangsidimpuan yaitu bahwa Manajemen Penghimpunan Dana yaitu program KOIN NU dan media sosial, rekening dan barcode pembayaran mempunyai pengaruh dalam pengumpulan dana. Berdasarkan data yang diperoleh bahwa jumlah pengumpulan dana KOIN NU lebih besar daripada media sosial, rekening dan barcode pembayaran.Manajemen pengeloaan dana dilakukan dengan cara cermat dan dicatat dalam pembukuan yang dibuat secara rinci mengenai jumlah dan infak yang diterima serta penyaluran dana tersebut. Manajemen pendistribusian dana LAZISNU Padangsidimpuan dilaksanakan pada 5 bidang yaitu sosial keagamaan, ekonomi, pendidikan, renovasi dan kesehatan.

\section{DAFTAR PUSTAKA}

Ahmad, N. (2021). PEMBERDAYAAN EKONOMI MASYARAKAT MELALUI ZAKAT PRODUKTIF DI NU CARE-LAZISNU KABUPATEN BANYUMAS [PhD Thesis]. IAIN Purwokerto.

Annisatry Lubis, E., Sissah, S., \& Addiarrahman, A. (2020). Pengaruh Persepsi Dan Kepercayaan Masyarakat Terhadap Gerakan KOIN LAZIS NU Provinsi Jambi [PhD Thesis]. UIN Sulthan Thaha Saifuddin Jambi.

Ansori, T. (2018). Pengelolaan Dana Zakat Produktif untuk Pemberdayaan Mustahik pada Lazisnu Ponorogo. Muslim Heritage, 3(1), 177-196.

JISFIM: Journal of Islamic Social Finance Management, Volume 2, No 1 Tahun 2021 http://jurnal.iain-padangsidimpuan.ac.id/index.php/JISFIM 
Astuti, O. S. (2020). Implementasi penghimpunan dan pendistribusian dana zakat untuk kesejahteraan mustahik pada LAZISNU Kota Kediri [PhD Thesis]. Universitas Islam Negeri Maulana Malik Ibrahim.

DAAIM, M. (2020). Model Pengelolaan Zakat NU CARE-LAZISNU Tingkat Provinsi Jawa Tengah [PhD Thesis]. IAIN KUDUS.

ISLAM, J. S. D. K. (n.d.). SEJARAH LEMBAGA 'AMIL ZAKAT, INFAK, DAN SHADAQAH NAHDLATUL ULAMA DAERAH ISTIMEWA YOGYAKARTA (LAZISNU DIY) TAHUN 2006- 2016 M.

Kharimah, I. (2019). Pengaruh Program Koin NU LAZISNU Kota Semarang terhadap Keberdayaan Masyarakat di Desa Wonolopo [PhD Thesis]. UIN Walisongo.

Maulana, R. R. (2020). Analisis Program Koin NU Peduli dalam pengelolaan infak pada LAZISNU MWC Klojen Kota Malang [PhD Thesis]. Universitas Islam Negeri Maulana Malik Ibrahim.

Nafiah, D. (2018). Efektivitas strategi digital marketing pada penghimpunan dana zakat, infak, dan shodaqoh/ZIS dengan pendekatan direct rating method/DRM: Studi Kasus NU CARE-LAZISNU Jakarta Pusat [PhD Thesis]. UIN Walisongo Semarang.

Rafi'i, R., Tarmizi, A., \& Badaruddin, B. (2020). ANALISIS FAKTOR-FAKTOR PENYEBAB KURANG MINAT MASYARAKAT MEMBAYAR ZAKAT DI LAZISNU KOTA JAMBI [PhD Thesis]. UIN Sulthan Thaha Saifuddin Jambi.

Rafiqi, I. (2019). Strategi Fundraising Zakat Infak Shadaqah di LAZISNU dan LAZISMU Kabupaten Pamekasan [PhD Thesis]. UIN Sunan Ampel Surabaya.

Rahman, H. (2019). Relevansi Penggunaan Istilah Infak dan Sedekah dengan Praktik Pengelolaan Dana Infak dan Sedekah di LAZISNU Se-Madura [PhD Thesis]. UIN Sunan Ampel Surabaya.

Sa'diyah, Y. H. (2020). Implementasi regulasi zakat terhadap kinerja amil zakat: Studi di kantor LAZISNU cabang Nganjuk [PhD Thesis]. Universitas Islam Negeri Maulana Malik Ibrahim.

Wiqoyati, Z. (2019). Strategi penghimpunan dana zakat infak dan sedekah (ZIS) pada lembaga amil zakat al Ihsan Jawa Tengah (LAZIS Jateng) cabang Pekalongan [PhD Thesis]. IAIN Pekalongan.

Yulianti, R. (2019). Efektivitas Pengelolaan Dana Koin Nahdlatul Ulama (Nu) Dalam Meningkatkan Kesejahteraan Masyarakat Ditinjau Dari Perspektif Ekonomi Islam Di Lembaga Amil Zakat, Infak Dan Sedekah Nahdlatul Ulama (Lazisnu) Kabupaten Jombang. 